Aloysio Marthins Araujo Junior Universidade Federal de Santa Catarina, UFSC

Email: aloysio.junior@ufsc.br (D) http://orcid.org/0000-0003-4674-0285

Recebido em: 25/05/2017 Aprovado em: 31/10/2017

\section{Formação inicial de professores de Geografia: aspectos estruturais para permanência e atuação na Escola Básica}

\author{
Aloysio Marthins Araujo Junior
}

\section{Resumo}

A nova lógica de acumulação capitalista requer trabalhadores e consumidores melhor treinados e qualificados, para produzirem produtos ou serviços ou para se utilizarem destes. A escola e o ensino devem também passar por uma nova reorganização, sendo avaliados por sua qualidade e eficiência. Quanto à formação de professores de Geografia e sua atuação, estes têm passado por profundas modificações no campo conceitual e de sua prática educativa. Tais formulações e práticas são centradas na meritocracia individual, sendo o mercado o grande regulador dos problemas sociais $\mathrm{e}$ econômicos. O desafio das universidades é estabelecer com a sociedade uma relação mútua e estar articulada em uma aprendizagem que ultrapasse os limites de cada disciplina, enfocando no desenvolvimento da cooperação, da pesquisa e da extensão, interrelacionadas aos currículos dos cursos. Contudo, estão intrinsecamente relacionadas aos recursos humanos $\mathrm{e}$ às infraestruturas já existentes. Conclui-se que além de uma formação inicial que busque maior aproximação com a realidade escolar, é preciso, posteriormente, que os profissionais da educação tenham à disposição melhores condições de trabalho e sejam valorizados em termos de remuneração, o que ainda está longe de ocorrer no Brasil, em termos gerais.

Palavras-chave: Formação de professores. Neoliberalismo e Educação. Carreira Docente. 


\begin{abstract}
Keywords:

Geography

Teaching.

Neoliberalism and

Education. Teaching

Career.

Initial training of teachers of geography, structural aspects for staying and acting in the basic school

The new logic of capitalist accumulation requires workers and consumers better trained and qualified to produce products or services or to make use of these. The School and education must also go through a new reorganization, being evaluated by your quality and efficiency. The training of teachers of geography and your performance, these have gone through profound changes in the conceptual field and your educational practice. Such formulations and practices are focused on individual meritocracy, being the market the great regulator of social and economic problems. The challenge for universities is to establish a mutual relationship with society and be articulated in a learning process that goes well beyond the limits of each discipline, focusing on the development of cooperation, research and extension, interrelated to course curriculums. However, are intrinsically related to human resources and the existing infrastructures. It is concluded that in addition to the initial training that seeks to be closer to the reality of the school, it is necessary, later, that the education professionals have better working conditions available, in addition to being valued in terms of remuneration, which is still far occur in Brazil in general terms.
\end{abstract}

\title{
Resumen
}

\section{Palabras-clave:}

Formación de

Profesores.

Neoliberalismo y

Educación. Carrera

Docente.
Formación inicial de profesores de geografía, aspectos estructurales para permanecer y actuar en la escuela básica

La nueva lógica de la acumulación capitalista requiere mejor trabajadores entrenados y cualificados para producir productos o servicios o para utilizar estos. La escuela y la enseñanza también deben aprobar una nueva reorganización, que está siendo evaluado por su calidad y eficiencia. En cuanto a la formación de profesores de la geografía y de sus operaciones, éstas han experimentado profundos cambios en el campo conceptual y su práctica educativa. Tales formulaciones y prácticas se centran en el mérito individual y el mercado es el gran regulador de los problemas sociales y económicos. El desafío para las universidades es establecer con la sociedad una relación sólida y articularse en un aprendizaje que supera los límites de cada disciplina, centrándose en la cooperación al desarrollo, la investigación y la extensión, con los programas de estudios relacionados entre sí. Sin embargo, son intrínsecamente relacionados con los recursos humanos y la infraestructura existente. Se concluye que además de la propia formación inicial que busca mayor aproximación con la realidad escolar, es necesario, posteriormente, que los profesionales de la educación tengan a disposición mejores condiciones de trabajo, además de ser valorados en términos de remuneración, lo que aún está lejos de ocurrir en Brasil, en términos generales. 


\section{Introdução}

Este artigo é parte da pesquisa intitulada Formação de professores de Geografia na Universidade Federal de Santa Catarina/Brasil: investigação a partir das disciplinas de estágios obrigatórios, financiada pelo Conselho Nacional de Desenvolvimento Científico e Tecnológico (CNPq), agência do Ministério da Ciência, Tecnologia e Inovação (MCTI), órgão do governo federal brasileiro. Nessa pesquisa, o objetivo principal é descrever, compreender e analisar a formação socioeconômica catarinense após a introdução de políticas neoliberais implementadas nos anos 1990 e interpretar como que se dá a formação de professores e o ensino de Geografia no estado, particularmente na Universidade Federal de Santa Catarina.

$\mathrm{O}$ artigo ora apresentado pretende discutir em termos gerais a formação de professores, tendo como enfoque a disciplina de Geografia e especificamente um dos aspectos que influenciam a carreira docente e a atuação profissional, considerando os contextos econômicos e políticos brasileiros, particularmente a partir da década de 1990. Para tanto, traz informações sobre questões salariais dos professores e discute como isso pode influenciar a prática docente de Geografia, não apenas para os profissionais que já estão atuando no mercado de trabalho mas também para aqueles que estão (estarão) iniciando sua jornada.

Historicamente, pode-se afirmar que a escola e a escolarização são instrumentos de dominação de uma classe burguesa sobre todo o conjunto da sociedade que se efetivaram durante o século XIX. Mais tarde, isso ficará mais evidente, no Brasil, a partir das reformas educacionais promovidas pelo Regime Militar (1964-1985) e, posteriormente, por governos neoliberais da década de 1990.

É necessário ainda considerar que a educação - especificamente, a Geografia - é reflexo da sociedade (brasileira), e ambas têm passado por grandes crises e transformações. Assim, torna-se imperioso discutir e analisar o papel da ciência e da técnica e o modo como se articula o ensino de Geografia nesse contexto, bem como contribuir com a Pedagogia da Educação Superior, a partir das exigências atuais da formação de docentes do Ensino Fundamental e Médio que propiciem elevar qualitativamente o nível do ensino.

\section{A evolução do pensamento geográfico e sua estruturação como ciência}

Nesta seção, não se pretende apresentar um longo histórico do desenvolvimento da ciência geográfica. Detalhes sobre as origens e evolução do pensamento geográfico podem ser obtidos em vários autores, tais como: Pereira (1999); Moraes (1999) e Moreira (1981), entre outros.

No entanto, pode-se afirmar que a partir do momento em que se tornaram mais complexas, as sociedades passaram a se utilizar da técnica como recurso material de sua existência ${ }^{1}$. Ao final do século XVIII, a introdução de máquinas no processo de produção de mercadorias levou a uma tecnicização da 
sociedade. Esta então passou a organizar-se em função das atividades produtivas e a distanciar-se da perspectiva natural. Isso significou um avanço tecnológico sem precedentes para a humanidade, subjugando a natureza às necessidades de ampliação da capacidade produtiva.

Até o século XIX, a discussão sobre o objeto da Geografia girou em torno de sua materialidade. Posteriormente, os estudos avançaram sobre as questões da circulação e concentração de capitais, estes de domínio imaterial (SORRE, 1984). Portanto, sob a égide contemporânea do capitalismo monopolista, que domina as relações sociais e políticas, tendo a técnica (tecnologia) se sobrepujado às questões econômicas, o geógrafo não pode subestimar o estudo deste mundo em transformação sem ampliar seu campo de visão, sob a pena de tornar seu olhar e compreensão da realidade obsoletos.

A Geografia tem passado por grandes transformações nas últimas décadas, especialmente a partir dos anos 70 do século XX, quando surge a chamada Geografia Crítica. Segundo seus representantes, ela emerge em função da necessidade de se criar uma alternativa à Geografia Tradicional, pois se questionava a Geografia ensinada nos livros didáticos e em salas de aula, essencialmente descritiva e sem aprofundamentos que explicassem a relação entre a sociedade e a natureza.

A literatura sobre a evolução do pensamento geográfico traz muitas informações e análises sobre as diferentes correntes geográficas, tais como o Determinismo, o Possibilismo, o Método Regional, a Geografia Pragmática e a Geografia Crítica. É preciso observar que várias outras correntes de pensamento surgiram nas últimas duas ou três décadas, como por exemplo, a Geografia Cultural e Humanística (Fenomenologia) ou a Geografia Ambiental ou Socioambiental, fundamentada numa visão sistêmica (teoria da complexidade).

Saliente-se que mesmo que uma determinada corrente não seja hegemônica entre os geógrafos, professores de geografia e/ou investigadores, isso não significa que não se pratique uma geografia "tradicional" ou qualquer outra referência teórica-metodológica. Na prática, observa-se, muitas vezes, uma corrente se sobrepondo e/ou se interpondo a outra, dialeticamente.

\section{Estrutura básica na formação de professores no Brasil}

No Brasil, a criação de um sistema de ensino formal e organizado como tal inicia-se mais propriamente a partir da década de 1930, em um momento de expansão das atividades econômicas, notadamente as industriais. Isso exigiu, por parte das autoridades governamentais, a criação de condições de maior acesso à educação - particularmente voltada ao trabalho industrial e a outros setores econômicos. Nesse contexto, surgem as primeiras faculdades e universidades, com os Cursos de Filosofia. Contudo, ainda não se contemplava a formação de professores para a Escola Básica, e, como não havia instituições voltadas propriamente à formação de professores, tais cursos passaram a assumir essa função. 
Desde o final dos anos 1960, as economias desenvolvidas já davam mostras de esgotamento em suas capacidades de crescimento e desenvolvimento econômicos. Isso se tornaria mais evidente em meados dos anos 1970, com o fim do sistema de Bretton Woods² e a elevação dos preços do petróleo em razão do envelhecimento dos parques produtivos - principalmente dos Estados Unidos da América - e da entrada de novos atores no comércio internacional (Japão e ex-Alemanha Ocidental em especial), entre outros acontecimentos.

Delineava-se uma crise da acumulação de capital e da rentabilidade capitalista praticadas até então. Para contornar ou minimizar tal situação, tornou-se necessário buscar a diversificação de produtos e serviços, aumentar a eficiência produtiva, reduzir custos, diminuir a influência do Estado sobre as atividades produtivas e aumentar a produtividade por trabalhador, tudo isso em acordo com o pensamento econômico liberal de então. Apregoava-se ainda a necessidade de novas formas de descentralização e territorialização produtiva, bem como a busca por novos e sofisticados mercados consumidores (ou seja, com maior capacidade de compra).

As transformações ocorridas a partir desse período colocaram o Estado como o grande adversário para o desenvolvimento das forças produtivas. Foi necessário, portanto, substituir o Estado Desenvolvimentista pelo Estado Regulador (CHARLOT, 2007). Entre outras, uma das funções desse novo Estado recai sobre a escola, pública ou particular, pois a nova lógica de acumulação capitalista passou a requerer trabalhadores e consumidores mais (in)formados e qualificados. Também se tornou imperioso aumentar o nível de formação básica, para a produção e utilização de novos produtos e serviços lançados no mercado, tais como máquinas de autoatendimento nos bancos, computadores pessoais, produtos de entretenimento doméstico etc.

Dessa forma, a escola e o ensino de modo geral também deveriam passar por uma nova (re)organização, sendo avaliados por sua qualidade e eficiência. No caso específico da gestão escolar, impôs-se a ela o dever de buscar parcerias com empresas e de ter maior inserção na comunidade da qual fazia parte, descaracterizando, com essas novas funções, o modo como funcionara até então. O professor passou a ser considerado um solucionador de problemas que deveria buscar inovações, mobilizar recursos locais e formar estudantes capacitados para o mercado de trabalho.

Tais formulações dão indícios da vigência de um pensamento e de práticas denominadas neoliberais, centradas na capacidade e eficiência individual, em que o mercado figura como o grande regulador dos problemas sociais, políticos e econômicos (a "mão invisível"). O neoliberalismo, grosso modo, pode ser caracterizado como um conjunto de medidas que diminui a atuação dos Estados nacionais. Segundo seus teóricos, os Estados não mais teriam as funções de fomentadores e articuladores do processo de desenvolvimento econômico e social, colocando-as sob responsabilidade dos agentes do mercado (iniciativa privada) $)^{3}$. 
No campo da educação, isso ficou evidenciado a partir do Relatório Delors, no qual salientava-se que os professores, historicamente, quase sempre davam muita ênfase na aquisição do conhecimento, mas sem um propósito claro para o aluno. Objetivamente, a proposição do Relatório foi indicar as denominadas quatro metas do milênio: (1) aprender a conhecer, (2) aprender a fazer, (3) aprender a conviver e (4) aprender a ser (DELORS, 1996).

Para os que advogam tal visão, o ensino público consome enormes recursos sem o efetivo retorno e portanto deve ser redimensionado (entenda-se direcionado para as classes mais populares), enquanto o ensino particular deve ser fortemente incentivado.

Desde a década de 1970, diferentes instituições internacionais têm tido participação e influência sobre os destinos de diferentes países latino-americanos no tocante à educação nesta perspectiva. As mais importantes são a Organização para Cooperação e Desenvolvimento Econômico ${ }^{4}$ (OCDE), que atua basicamente entre os países ricos; o Fundo Monetário Internacional (FMI), cuja missão é evitar ou superar crises, como aconteceu nos anos 80 do século XX, a partir de repasses financeiros para os países membros; o Banco Mundial (BM), que busca combater a pobreza em longo prazo, por meio de financiamentos em áreas sociais (particularmente a educação); e a Organização Mundial do Comércio (OMC), que não tem poder de decisão, mas regula - por meio de convênios e arbitragem - o comércio entre os países signatários.

$\mathrm{Na}$ atualidade, a formulação e implementação de políticas voltadas à formação de professores compete a todas as esferas governamentais (governos federal, estaduais e municipais), para garantir a exigência mínima contida na legislação educacional. Desde 2007, as licenciaturas passaram, obrigatoriamente, a ser plenas, isto é, com formação superior ${ }^{5}$. No sentido de formar mais professores, foram publicados vários documentos e postas em prática diversas ações voltadas a esse objetivo. Todo curso de nível superior é regido por Diretrizes Curriculares Nacionais (DCN) específicas (BRASIL, 2002), nas quais constam a carga horária mínima e os currículos, bem como a exigência de que cada um deles elabore seu respectivo Projeto Político-Pedagógico (PPP), entre outras obrigações.

No Brasil, a graduação superior em Pedagogia habilita o egresso a ministrar aulas apenas para a Educação Infantil ( $1^{\circ}$ ao $5^{\circ}$ ano). Na graduação de qualquer área, tem-se o diploma/grau de bacharel; todavia, esse profissional não está habilitado a ministrar aulas. Normalmente, os cursos superiores oferecem as duas modalidades: bacharelado e licenciatura. O graduando pode optar pelas duas áreas, de acordo com o Regimento Interno de cada Instituição de Ensino Superior (IES).

Nas licenciaturas, cujo objetivo é formar professores para atuar no Ensino Fundamental $\left(6^{\circ}\right.$ ao $9^{\circ}$ ano) e/ou Ensino Médio, são necessárias, além das disciplinas comuns aos bacharelados, as específicas, tais como: Teorias da Educação, Psicologia da Educação, Desenvolvimento e Aprendizagem, Organização Escolar, Didática do Ensino, Metodologia de Ensino, Estágios Obrigatórios, entre outras. A 
carga horária das licenciaturas também é diferente da dos bacharelados. Recentemente, a formação inicial

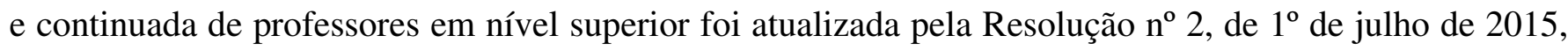
do Conselho Nacional de Educação, com previsão para ser implementada em 2017/2018.

\section{Organização dos cursos de Geografia no Brasil}

Historicamente, pode-se caracterizar a formação de professores a partir de dois paradigmas: o paradigma padrão e o paradigma reflexivo (SILVA, 2008).

No paradigma padrão, a transmissão de conhecimento e a absorção de informações se davam a partir do professor como autoridade máxima do processo ensino-aprendizagem. Já no paradigma reflexivo, existe uma comunidade de investigação, reflexão e senso crítico, na qual o professor, passível de falhas, também está sujeito à autocrítica. O conhecimento do mundo é ambíguo, equívoco e explicável (com todas as suas contradições).

Nesse sentido, toma forma o que vem a ser formação. Pode-se inferir que significa preparar os cidadãos para a vida, para um bom desempenho em sociedade. Sob esse aspecto, é possível identificar três dimensões essenciais que caracterizam a formação: a) uma dimensão instrutiva, na qual o profissional tem que ser instruído. Supõe-se que tenha conhecimentos e habilidades; b) uma dimensão desenvolvedora, que coloca o estudante em contato com o objeto de sua profissão, ou seja, o desenvolvimento de seus modos de atuação; e c) uma dimensão educativa, que requer preparar o acadêmico para viver em sociedade. Tal concepção supõe, ademais, que essas três dimensões se desenvolvam indissoluvelmente unidas entre si, durante todo o percurso acadêmico.

Assim, as dimensões do conteúdo de ensino devem se voltar aos conhecimentos (cognitivo), às habilidades (procedimental) e aos valores afetivos e atitudinais (SILVA, 2008). A transformação que se produzia no paradigma padrão estava centrada nos aspectos cognitivos, ao passo que, no paradigma reflexivo, busca-se a integração dialética dos aspectos cognitivos com os significativos, conscientes, de compromisso social.

A conceptualização da concepção dialética da formação auxilia na compreensão da teoria e da prática como elementos das práxis pedagógicas, em que a prática, sendo reflexiva, remete a uma busca teórica para melhor análise e entendimento desta própria prática, oferecendo subsídios para transformá-la.

No campo da atividade profissional, pode-se considerar que a prática docente é uma sucessão particular de construção de conhecimentos técnico-científicos associados à experiência e ao percurso pessoal do professor, para que ele reinterprete, intervenha e crie modos de realizar ações educativas em situações de ensino e aprendizagem.

É consenso entre os profissionais que atuam no ensino que a escola, principalmente a pública, estruturada da maneira com que está, pouco permite ousar em termos de inovações educativas ou 
conceituais. Há pouco mais de três décadas, as condições de trabalho dos professores têm sido precarizadas, normalmente com cargas horárias elevadas e baixos salários, além de outros problemas. Nesse caso, o professor da escola secundária não se torna produtor de novos conhecimentos, mas reprodutor de outras situações, por vezes distante de sua região e da comunidade em que está inserido. A atividade investigativa fica restrita às Universidades, reafirmando a elitização do ensino e da produção científica academizada.

Podem-se estabelecer diferentes parâmetros de análise para a crise do ensino de modo geral e do ensino da Geografia em particular. Essa análise compreende principalmente a crise estrutural, que se desdobra em: (a) político-ideológica (liberalismo) e (b) epistemológica (inclui a crise do positivismo e seu discurso, assim como a questão metodológica). Engloba ainda a crise operacional, dividida em: (i) curricular e (ii) didático-pedagógica. E, por fim, a crise funcional, que se refere à inadequação da formação de seus egressos ao mercado de trabalho e aos problemas de identidade e legitimidade dos docentes de Geografia.

Em 3 de abril de 2001, foi aprovado o Parecer nº 492, acerca das Diretrizes Curriculares Nacionais dos cursos de Filosofia, História, Geografia, Serviço Social, Comunicação Social, Ciências Sociais, Letras, Biblioteconomia, Arquivologia e Museologia remetidas pela Secretaria de Educação Superior (SESu) do MEC para apreciação por parte da Câmara de Educação Superior (CES) do Conselho Nacional de Educação (CNE), que aprovou por unanimidade as referidas Diretrizes.

De acordo com as Diretrizes Curriculares Nacionais do curso de Geografia, de 2001,

\begin{abstract}
A geografia vem evoluindo, nas últimas décadas, tanto pela introdução e aprofundamento de metodologias e tecnologias de representação do espaço (geoprocessamento e sistemas geográficos de informação, cartografia automatizada, sensoriamento remoto etc.) quanto no que concerne ao seu acervo teórico e metodológico em nível de pesquisa básica (campos novos ou renovados como geo-ecologia, teoria das redes geográficas, geografia cultural, geografia econômica, geografia política e recursos naturais etc.), quanto em nível de pesquisa aplicada (planejamento e gestão ambiental, urbana e rural) (BRASIL, 2002, p. 10).
\end{abstract}

As DCN estabelecem como princípios norteadores alguns itens que deverão constar nos PPPs das IES; estas, porém, gozam de liberdade e flexibilidade para se adequarem às demandas de seus respectivos públicos (estudantes, professores, técnicos administrativos). Os referidos princípios são os seguintes: 1. Perfil do Formando; 2. Competências e Habilidades (Gerais e Específicas); 3. Organização do Curso; 4. Conteúdos Curriculares; 5. Estágios e Atividades complementares; 6. Conexão com a Avaliação Institucional.

\title{
4 A profissionalidade e a profissão docente
}

De acordo com dados do Instituto Nacional de Estudos e Pesquisas Educacionais Anísio Teixeira (Inep), em 2010 o Brasil tinha 829.286 acadêmicos matriculados que concluíram cursos superiores 
voltados à formação de professores, entre os quais 6.753 professores de Geografia em cursos presenciais (considerando-se universidades públicas e privadas).

Em 2012, também com dados do Censo do Ensino Superior do Inep (2012), o número de vínculos de alunos em universidades públicas (federais, estaduais e municipais) era de 495.663; e em universidades, faculdades e centros de ensino privados, de 420.930, totalizando 916.593. Em 2013, os cursos de Geografia no Brasil contavam com 48.792 matriculados (INEP, 2012).

Os números podem parecer expressivos, porém ainda há necessidade de mais professores em praticamente todas as áreas do Ensino Fundamental e Médio. Isso se deve a vários fatores, tais como a obrigatoriedade de escolarização básica (que aumenta o número de alunos matriculados), a exigência de diploma de Ensino Médio para a entrada no mercado de trabalho, o aumento vegetativo da população, entre outros.

Além de ser um fator importante para o estímulo ao ingresso e também para a permanência na carreira docente, os baixos salários têm desestimulado os jovens (e antigos) professores. Contudo, outros aspectos devem ser considerados, tais como as condições de trabalho (salas lotadas, falta de materiais e/ou recursos didáticos e pedagógicos, ausência de uma carreira docente que faça jus ao tipo de trabalho exercido etc.).

A questão das relações entre capital e trabalho, no Brasil, foram instituídas somente a partir da década de 1930, a partir da edição de leis que garantiram alguns direitos ao trabalhador. Tais direitos abrangem todas as ocupações profissionais dentro de uma determinada categoria de emprego, seja ele professor, comerciário, metalúrgico, bancário, construtor civil, enfermeiro etc. Cada trabalhador recebe um salário base, chamado de Piso Salarial, que é sua garantia de recebimento dentro de seu grau profissional.

Dessa forma, a Tabela 1 e o Quadro 1 indicam uma organização por áreas de atuação profissional e salário médio encontradas no mercado de trabalho privado. Para fins didáticos, não estão contempladas todas as categorias profissionais, mas algumas representativas e comparadas com os salários dos professores da escola básica (Tabela 2).

Tabela 1 - Brasil: Piso salarial por áreas - 2015 (apenas os salários médios para fins de comparação) (continua)

\begin{tabular}{l|c|c}
\hline \multicolumn{1}{c|}{ Áreas $^{(\mathbf{1})}$} & $\begin{array}{c}\text { Valores em Reais (R\$) (BRL) } \\
\text { Salário Médio }^{(\mathbf{( 4 )})}\end{array}$ & Equivalente em US\$ (USD) $^{(\mathbf{5})}$ \\
\hline $\begin{array}{l}\text { Administrativa e Apoio } \\
\text { Encarregado de Serviços Administrativos }\end{array}$ & 5.015 & 1,63 \\
Motorista de Diretoria & 2.476 & 805 \\
Auxiliar de Escritório & 1.312 & 426 \\
Porteiro & 1.323 & 430 \\
Financeira & & 2,864 \\
Coordenador Financeiro & 8.809 &
\end{tabular}


Auxiliar Financeiro

Contabilidade

Coordenador de Contabilidade

Auxiliar de Contabilidade

Logística

Coordenador de Logística

Auxiliar de Logística

\section{Manutenção}

Coordenador de Manutenção

Auxiliar de Manutenção

\section{Marketing}

Coordenador de Marketing

Tabela 1 - Brasil: Piso salarial por áreas - 2015 (apenas os salários médios para fins de comparação) (continua)

\begin{tabular}{|c|c|c|}
\hline Áreas ${ }^{(1)}$ & $\begin{array}{c}\text { Valores em Reais }(\mathrm{R} \$)(\text { BRL })^{(2)(3)} \\
\text { Salário Médio }^{(4)} \\
\end{array}$ & Equivalente em US\$ (USD) ${ }^{(4)}$ \\
\hline \multicolumn{3}{|l|}{ Planejamento e Controle da Produção } \\
\hline Coordenador de PCP & 6.545 & 2,128 \\
\hline Auxiliar de PCP & 1.369 & 445 \\
\hline \multicolumn{3}{|l|}{ Recursos Humanos } \\
\hline Coordenador de Recursos Humanos & 8.304 & 2,700 \\
\hline Médico do Trabalho (4 H) & 5.089 & 1,654 \\
\hline Auxiliar de Enfermagem do Trabalho & 2.220 & 721 \\
\hline Técnico de Segurança do Trabalho & 3.338 & 1,085 \\
\hline \multicolumn{3}{|l|}{ Tecnologia da Informação } \\
\hline Técnico de Informática & 1.841 & 598 \\
\hline \multicolumn{3}{|l|}{ Teleatendimento } \\
\hline Operador de Teleatendimento $(6 \mathrm{H})$ & 773 & 251 \\
\hline \multicolumn{3}{|l|}{ Vendas } \\
\hline Auxiliar de Vendas & 1.393 & 452 \\
\hline \multicolumn{3}{|l|}{ Bolsa de Estágio (6 Horas) } \\
\hline Estagiário (Penúltimo Ano) & 1.124 & 365 \\
\hline Estagiário (Último Ano) & 1.326 & 431 \\
\hline
\end{tabular}
Notas:

Fonte: Piso Salarial das Profissões (2015a, 2015b). Adaptada pelo autor.

(1) Nem todos os cargos acima descritos necessitam de curso superior (caso de auxiliares e outros cargos com menor grau de exigência).

(2) De acordo com a Lei as empresas não devem pagar menos que um salário mínimo; sendo assim, os salários são obtidos através de uma média nacional. A região do país também possui influência na hora de definir esses valores.

(3) A jornada média semanal é de 40 horas.

(4) Salário Mínimo Nacional a partir de $1^{\circ}$ jan. 2015 era R\$ 788,00, o que equivalia a U\$ 256,22.

(5) Cotação oficial em 4 de maio de 2015: 1 Real Brasil/BRL = 0,325161 Dólar dos EUA/USD. Fonte: Banco Central do Brasil (2015). 
Quadro 1 - Outras profissões de nível superior

\begin{tabular}{|l|l|c|}
\hline \multicolumn{1}{|c|}{ Profissão } & \multicolumn{1}{c|}{ Requisitos } & \multicolumn{1}{c|}{ Valores em Reais } \\
\hline Engenheiro Agrônomo & Domínio de novas tecnologias agrícolas e visão estratégica. & 8 a 16 mil \\
\hline $\begin{array}{l}\text { Pngenheiro de } \\
\text { Produção }\end{array}$ & Inglês fluente além de saber trabalhar em grupo. & $\begin{array}{l}5 \text { ou } 6 \text { mil (inicial) } \\
25 \text { a } 35 \text { mil (> } 10 \text { anos de } \\
\text { experiência) }\end{array}$ \\
\hline $\begin{array}{l}\text { Profissional de } \\
\text { Pesquisa e } \\
\text { Desenvolvimento }\end{array}$ & Formação nas áreas de engenharia, química e biologia. & 13 a 17 mil \\
\hline $\begin{array}{l}\text { Analista de Mídias } \\
\text { Sociais }\end{array}$ & $\begin{array}{l}\text { Formação em marketing, relações públicas, jornalismo e } \\
\text { áreas afins, além do inglês fluente. }\end{array}$ & 8 a 15 mil \\
\hline $\begin{array}{l}\text { Gerente de Marketing e } \\
\text { Eventos }\end{array}$ & $\begin{array}{l}\text { Domínio de inglês e de um terceiro idioma. Formação em } \\
\text { propaganda e marketing, publicidade, relações públicas, } \\
\text { produção de eventos e áreas afins. }\end{array}$ & 10 a 15 mil \\
\hline \begin{tabular}{l} 
Diretor de Logística \\
\hline
\end{tabular} & \multicolumn{1}{c}{ - } & 20 a 50 mil \\
\hline
\end{tabular}

Fonte: Piso Salarial das Profissões (2015a, 2015b). Adaptado pelo autor.

A Lei $\mathrm{n}^{\circ} 11.738$, de 16 de julho de 2008 (BRASIL, 2008), instituiu o piso salarial nacional para os professores da Escola Básica, obrigando governos estaduais e municipais a aplicá-la. No entanto, há estados e municípios que não a cumprem, alegando falta de recursos. Mais recentemente, a Lei no 12.994, de 17 de junho de 2014 (BRASIL, 2014), alterou a Lei anterior e incluiu outras categoriais profissionais, notadamente na área da Saúde.

Tabela 2 - Piso salarial na Educação Básica (válido a partir de $1^{\circ}$ de jan. de 2015)

\begin{tabular}{lcc}
\hline \multicolumn{1}{c}{ Etapa } & Valores em Reais & \multicolumn{2}{c}{ Equivalente em } \\
USD $^{(\mathbf{4})}$ & $(\mathbf{R} \mathbf{( \mathbf { 1 } ) ( \mathbf { 2 } ) ( \mathbf { 3 } )}$ & 266,88 \\
\hline Educação Infantil (escolas que só possuem Educação Infantil) & 927,71 & 301,42 \\
Educação Infantil (até o 5 ano do Ensino Fundamental) & $1.036,66$ & 337,08 \\
$6^{\mathbf{0}}$ ao $9^{\mathbf{0}}$ ano do Ensino Fundamental & $1.078,88$ & 390,52 \\
Ensino Médio & $1.201,02$ & 371,41 \\
Ensino Técnico & $1.142,24$ & 545,09 \\
Pré-Vestibular & $1.676,40$ & 5 \\
\hline
\end{tabular}

Notas:

Fonte: Tabela Salarial de Professores (2015). Adaptada pelo autor.

(1) Valores calculados para jornada semanal de 22 horas.

(2) Sobre o piso salarial devem ser aplicados $5 \%$ de horas-atividades. Professores "aulistas" (que recebem apenas pelas aulas efetivamente ministradas) também têm que calcular o descanso semanal remunerado (DSR).

${ }^{(3)} \mathrm{O}$ piso dos professores mensalistas (até o $5^{\circ}$ ano do Ensino Fundamental) refere-se à jornada máxima de 22 horas semanais.

(4) Cotação oficial em 4 de maio de 2015: 1 Real Brasil/BRL = 0,325161 Dólar dos EUA/USD. Fonte: Banco Central do Brasil (2015).

No Gráfico 1, traz-se informações sobre a evolução do piso salarial para os professores, válido para todo o território nacional, considerando os profissionais com formação em nível médio, na 
modalidade Normal (Magistério), exercendo uma jornada de trabalho semanal de 40 horas e atuando na rede pública de ensino.

Gráfico 1 - Evolução do Piso Salarial para Professores

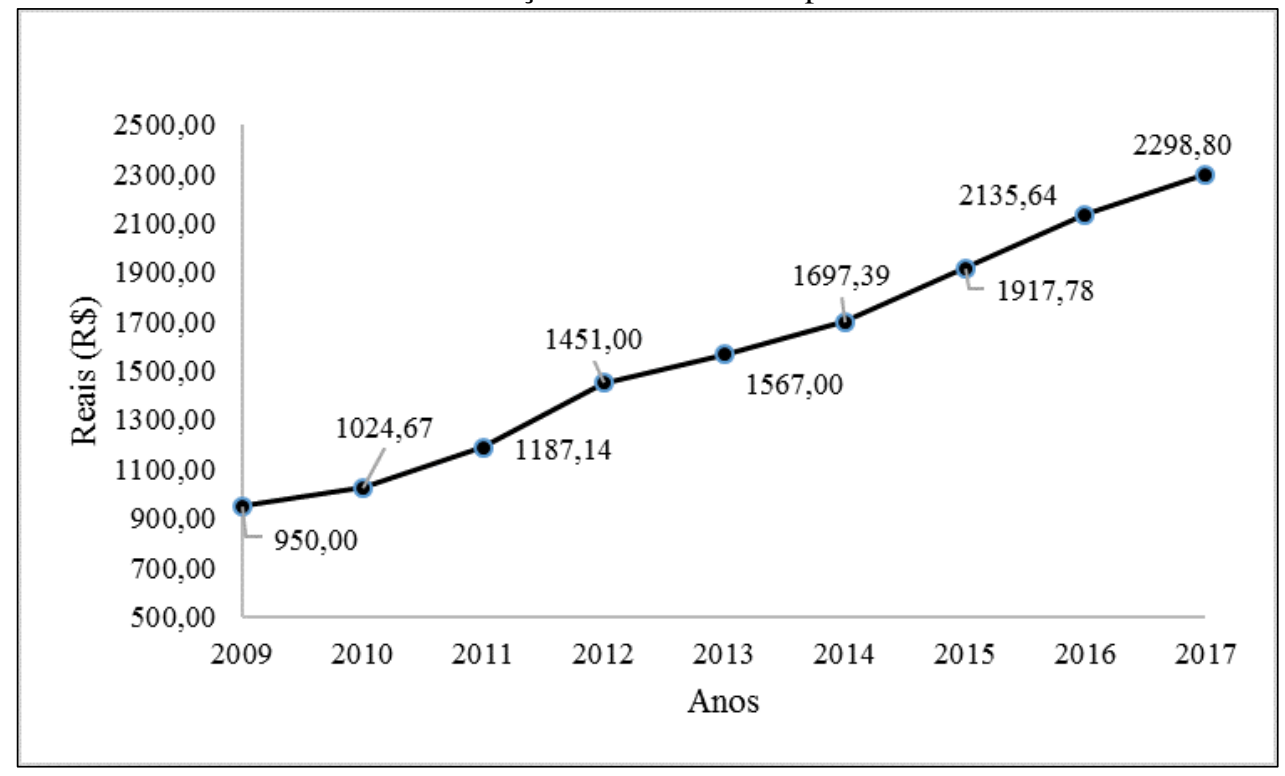

Fonte: Piso Salarial dos Professores (2017). Adaptado pelo autor.

Especificamente no estado de Santa Catarina, para os docentes com Licenciatura Plena, em 2014, o vencimento básico era de R $\$ 1.706,08$ (aproximadamente US\$ 457,22) ${ }^{6}$, acrescidos de $20 \%$ de horasatividades (preparação de aulas, correção de trabalhos, avaliações etc.), para uma jornada semanal de 40 horas (CONFEDERAÇÃO NACIONAL DOS TRABALHADORES EM EDUCAÇÃO, 2014) ${ }^{7}$.

Gráfico 2 - Brasil: Evolução do Salário Necessário e Nominal

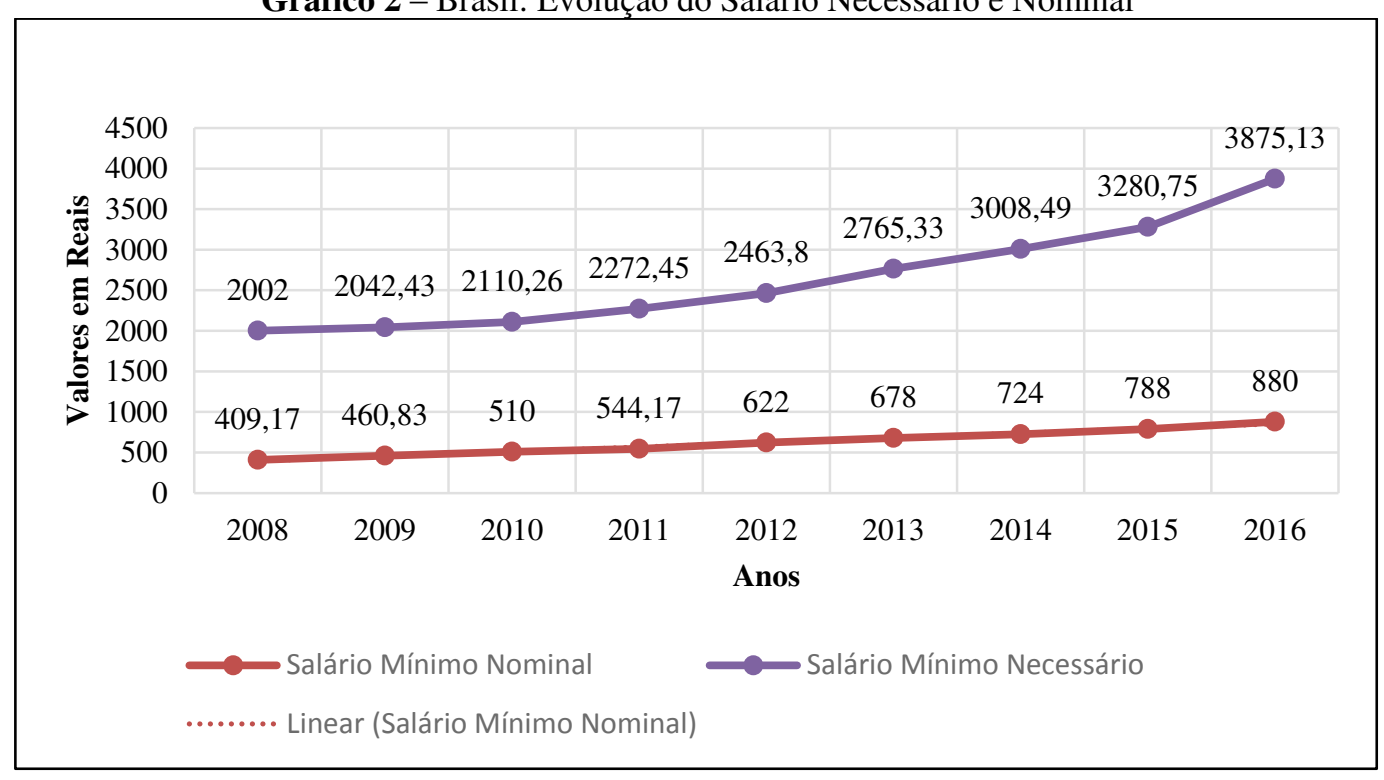

Fonte: Dieese (2017). Adaptado pelo autor. 
Contrastando-se as informações dos Gráficos 1 e 2, observa-se que os reajustes dos pisos salariais dos professores não acompanharam o salário mínimo necessário, de acordo com os levantamentos e estudos do Departamento Intersindical de Estatística e Estudos Socioeconômicos (Dieese).

Também a título de equiparação, na Tabela 3 há dados sobre salários em outros países, sejam eles “desenvolvidos" ou "emergentes". Nota-se a grande defasagem dos salários pagos por outros países em comparação com o Brasil.

Tabela 3 - Salário anual dos professores nas instituições públicas de Ensino Fundamental dos países da OCDE - 2012

\begin{tabular}{|c|c|}
\hline País & Salários (US\$) $)^{(1)}$ \\
\hline Luxemburgo & 66.085 \\
\hline Alemanha & 50.007 \\
\hline Estados Unidos & 36.333 \\
\hline Finlândia & 32.148 \\
\hline Média da OCDE & 29.411 \\
\hline Coreia do Sul & 28.591 \\
\hline Inglaterra & 28.321 \\
\hline Itália & 27.786 \\
\hline Japão & 27.067 \\
\hline França & 26.247 \\
\hline Grécia & 18.718 \\
\hline Chile & 17.770 \\
\hline México & 15.556 \\
\hline Polônia & 11.389 \\
\hline Brasil & 10.375 \\
\hline Indonésia & 1.560 \\
\hline
\end{tabular}

Fonte: OCDE (2014). Adaptada pelo autor.

Nota:

(1) Ajustados pela paridade do poder de compra (PPC).

Em 2015, foi divulgada uma pesquisa encabeçada pela Insider Monkey (DUTTA, 2015) sobre os 12 melhores salários médios anuais no mundo, cujos alguns dados podem ser conferidos na Tabela 4. Mesmo que esta pesquisa considere apenas os salários pagos aos profissionais com no mínimo 15 anos de experiência e utilize metodologia diferente da OCDE, ainda assim os salários pagos no Brasil não estão nesta lista, e os valores confirmam os dados da OCDE, listados na Tabela 3.

Tabela 4 - Professores: 10 melhores salários médios anuais - 2015

\begin{tabular}{ccc}
\hline Países & Colocação & Valor (US\$) \\
\hline Luxemburgo & $1^{\text {o }}$ & 97.808 \\
Suíça & $2^{\text {o }}$ & 68.849 \\
Alemanha & $3^{\text {o }}$ & 64.289
\end{tabular}




\begin{tabular}{ccc} 
Holanda & $4^{\circ}$ & 59.894 \\
Canadá & $5^{\circ}$ & 56.422 \\
Irlanda & $6^{\circ}$ & 54.954 \\
Dinamarca & $7^{\circ}$ & 53.000 \\
Bélgica & $8^{\circ}$ & 49.185 \\
Austrália & $9^{\circ}$ & 48.937 \\
Coreia do Sul & $10^{\circ}$ & 48.181 \\
\hline \multicolumn{2}{c}{ Fonte: Dutta (2015). Adaptada pelo autor. }
\end{tabular}

As informações constantes nas Tabelas 1 a 4, no Quadro 1 e nos Gráficos 1 e 2 demonstram que os salários dos professores da Educação Básica estão muito distantes dos de outras categorias profissionais, ainda que, por vezes, haja exigências e/ou formações semelhantes, e mesmo do salário pago aos professores desta etapa de ensino em países com o mesmo nível de desenvolvimento econômico e social brasileiro - ou até abaixo. É evidente que o Ensino é considerado uma das carreiras mais concorridas em vários países, que rapidamente reconheceram a importância de bons educadores para o objetivo final da construção de um sistema de ensino de qualidade, oferecendo salários mais atrativos para os melhores profissionais. O que, em última análise, representa um círculo virtuoso para o desenvolvimento econômico e social de um país. Isso demonstra que a atração de jovens para a carreira do magistério fica comprometida se for considerada apenas esta motivação.

Contudo, é evidente que apenas bons salários não são suficientes para atrair e manter os profissionais na carreira docente. Para o desenvolvimento de um trabalho ancorado na qualidade do processo de ensino e aprendizagem é fundamental que haja estrutura material para o professor e para os estudantes - salas equipadas com mapas, computadores, materiais didáticos diversos etc. Além disso, infelizmente, há outros fatores externos, como por exemplo, o papel que a imprensa (televisionada e/ou escrita) tem na formação da “opinião pública”. Raramente é divulgada uma ação positiva, sendo ressaltados, com grande repercussão, fatos negativos, por vezes discriminando a escola pública. Em suma, todos esses fatores fazem com que a atração de novos professores fique bastante comprometida.

Para alterar esse quadro, o estímulo à carreira docente deve ser priorizado pelos governos, em todos os níveis. Deve-se considerar também que o professor não é um simples reprodutor de conhecimentos desenvolvidos por outros profissionais. Na Escola Básica, o professor deve ser também um pesquisador - seja na busca de materiais para suas aulas, seja colocando problemas para que os estudantes tentem resolver (DEMO, 1998). Nesse caso, o professor passa a ser um importante agente de transformação educativa, como um orientador de estudos. Demo (2014), em entrevista para o sítio “Observatório da Educação", reafirma sua proposição: ao nascer, com a curiosidade da criança, a necessidade de confrontar-se com a realidade, com o 
desafio de ordenar mentalmente o mundo em que se vive. Ressalta-se, nestas fases iniciais, o lado mais pedagógico da pesquisa, tendo em vista aprimorar a capacidade de argumentar (não o argumento de autoridade, mas a autoridade do argumento), de elaborar textos próprios, de cultivar autoria e autonomia. A pesquisa deve acontecer no cotidiano da escola e também fora dela, em atividades como "lição de casa", a qual continua importante, se for tarefa de pesquisa, não de reprodução instrucionista.

Outro fator que contribui para o melhor desempenho docente e traz como reflexo a qualidade de ensino é a relação do número de alunos por professor. No Brasil não há uma lei que estipule o máximo de alunos por sala de aula. Mesmo no Plano Nacional de Educação aprovado em 2015 este assunto não foi contemplado. O que vigora é que cada escola defina a quantidade de alunos considerando a demanda, o quadro de professores e a infraestrutura disponível. Ou seja, é consenso entre educadores que um número menor de alunos por turma permite ao professor dar atenção mais individualizada, interferindo positivamente no processo ensino-aprendizagem.

\subsection{Ensino e prática docente em Geografia no período recente}

Para ensinar, e não apenas Geografia, é preciso professores que estejam comprometidos com a ciência geográfica e com a formação de jovens para a cidadania. E isso só pode ser realizado se os docentes tiverem condições de trabalho justas e se houver melhorias no sistema de ensino como um todo. É pertinente apontar que apenas melhor remuneração para os professores não é suficiente para que o processo de ensino-aprendizagem se transforme para melhor. É preciso criar outras formas de contratação de professores e estabelecer critérios para a sua permanência na escola, sendo a dedicação exclusiva um dos fatores de primeira ordem para a consecução de tais melhorias. Aliado a isso, é importante propiciar ao professor a oportunidade de elaborar seus materiais de aula - textos, imagens, vídeos etc. - de acordo com as características de seus estudantes e em conjunto com estes, a fim de que ele possa criar as condições para o processo de ensinar e aprender.

Ainda seguindo esse raciocínio, a formação de professores deve ser uma política de Estado, com investimentos em laboratórios, infraestruturas, materiais de apoio, qualificação e atualização constante do quadro docente (principalmente para aqueles que atuam nos cursos de licenciatura). Modificar as matrizes curriculares seria um primeiro passo. É preciso também reduzir a proporção professor/aluno, tendo em vista que salas com número menor de estudantes permitem ao professor conhecer as necessidades e potencialidades individuais. Os recursos tecnológicos devem ser utilizados como mais uma ferramenta didática, a fim de contemplar o que os estudantes já têm acesso ${ }^{8}$. A escola ainda não consegue se valer dos avanços da internet como uma ferramenta de trabalho para professores e o alunos. É claro que tudo isso demandará mais estudos e aperfeiçoamentos, mas o Brasil já está atrasado - principalmente a escola pública - levando-se em conta as várias possibilidades e recursos que a sociedade atual oferece.

Outros desafios devem ser encarados, como por exemplo: 
i) Matricular as crianças de 4 e 5 anos na pré-escola, pois, a partir de 2016, a matrícula entre 4 e 17 anos se tornou obrigatória. Pelo sistema de ensino brasileiro, os municípios são responsáveis pelo Ensino Infantil e Fundamental, recaindo sobre as prefeituras o ônus de oferecer vagas nas escolas (mesmo que as prefeituras recebam auxílio federal, os recursos ainda são insuficientes para cobrir a demanda);

ii) Com o Ensino Fundamental ( $1^{\circ}$ ao $9^{\circ}$ ano) praticamente universalizado, a discussão educacional deve buscar a qualidade em detrimento da quantidade. Um exemplo é a necessidade de debater quais conteúdos curriculares são mais convenientes, observando o projeto pedagógico de cada unidade escolar;

iii) Dar um atendimento mais completo ao aluno, flexibilizando o currículo com uma infraestrutura didática mais complexa;

iv) Aumentar o investimento e efetuar o regime de colaboração entre Municípios, Estados e União;

v) Promover uma gestão democrática da escola, com gestores escolhidos dentro da própria comunidade escolar e em diálogo com as famílias/responsáveis;

vi) Maior proximidade entre Escola e Universidade, considerando que é no Ensino Superior que se formam os futuros profissionais da educação. No presente, inexiste ou há pouquíssimas parcerias entre estas instituições de ensino (exceto o Programa Institucional de Bolsa de Iniciação à Docência/Capes, que nos últimos dois anos tem reduzido o número de bolsas para os estudantes de graduação e para os professores supervisores das IES);

vii) Planejamento visando ao médio e ao longo prazos. No Brasil, tais planejamentos se acabam quando finda um governo - em qualquer nível. Em outros termos, é preciso tratar a educação como um setor nevrálgico, seja do ponto de vista econômico, social ou cultural.

Tudo isso considerado, é pertinente entender que as modificações deverão ser profundas e exigirão processos de aplicação e avaliação constantes.

\section{Considerações Finais}

As exigências que o capital internacional tem feito aos países em desenvolvimento, principalmente desde a última década do século XX, vêm transformando as necessidades de educação (formal) das classes trabalhadoras, em vista da maior demanda por aperfeiçoamento técnico. Diante disso, a questão que se coloca é discutir e propor alternativas viáveis sobre o papel das Universidades (que formarão os professores para o Ensino Fundamental e Médio) diante de um mundo em rápida transformação, instado a atender às determinações do grande capital, que muitas vezes não se coadunam com as necessidades da sociedade.

Isso tem relação com a crença de que a exaltação à tecnologia seria a solução para todos os males da humanidade. Entretanto, a transformação da tecnologia em mercadoria, portanto passível de ser comercializada, coloca os países subdesenvolvidos no papel de consumidores de novas tecnologias, o que amplia ainda mais as desigualdades na divisão internacional do trabalho. Sendo assim, o discurso atual de 
governos, Organismos Internacionais e Organizações não Governamentais (nacionais ou estrangeiras) em relação ao papel das Universidades (públicas ou privadas) apregoa a modificação de sua função como produtora de conhecimento científico para mero apêndice do capital, dando uma 'utilidade' ao seu papel social. Com isso as Universidades se tornam produtoras de um saber voltado ao mercado de trabalho, excluindo a pesquisa como fonte básica na aquisição de novos conhecimentos.

$\mathrm{O}$ atual discurso neoliberal de acesso à escolarização procura alternativas para a resolução dos problemas sociais a partir da lógica do mercado, condicionando professores a buscar uma formação individual, a fim de responsabilizá-los pelos fracassos no processo ensino-aprendizagem. Entretanto, não é individualizando o profissional da educação que se conseguirá melhorar a qualidade do ensino e a própria sociedade, pois o professor e o educando estão inseridos num contexto plurissocial, com dinâmicas que fogem às leis de mercado.

De outra parte, a fragmentação do ensino demonstra as carências de uma universalização do saber; isto é, ao ser compartimentalizado, o conhecimento assume uma perspectiva 'mais técnica'. Devido às necessidades de expansão econômica, reduz-se a função do professor ao papel de mero reprodutor de conhecimentos originados em contextos diversos do educacional e alheios ao ambiente de sua comunidade. Aliada a tal fato, a precarização da profissão docente, principalmente por não dar estabilidade no emprego e razoáveis condições de trabalho, entre outros problemas, tem reduzido ainda mais os níveis de escolarização, além de dar causa à desmotivação profissional.

Tais fatores, somados às exigências próprias da profissão (atualização constante, habilidades de trabalho em equipe, facilidade de transmissão de exposição de ideias, criatividade etc.), aos baixos salários (o que se traduz em maior carga horária e estresse), à insegurança nas salas de aula, entre outras questões, desestimulam os jovens a optar por esse tipo de atividade profissional. Ou seja, as graduações em licenciatura, que formarão os futuros professores da Escola Básica, não têm conseguido atrair muitos jovens.

Portanto, é necessário criar e se utilizar de metodologias e instrumentos que busquem a interação entre a construção e a reconstrução do conhecimento numa perspectiva de totalidade, de tal modo que o educando possa refletir sobre o presente/passado e discutir o futuro numa ação recíproca entre a sociedade, a natureza e a comunidade em que está inserido.

\footnotetext{
Notas

${ }^{1}$ Técnica ou tecnologia pode ser definida como um método de se fazer alguma coisa. A utilização deste método exige três elementos essenciais: informação sobre este método, como empregá-lo e como compreendê-lo (DAHLMAN; WESTPHAL, 1983).

${ }^{2}$ A Conferência de Bretton Woods (EUA) ocorreu entre os dias $1^{\circ}$ e 22 de julho de 1944, com a participação de 44 países. Entre os participantes, destacaram-se os países do bloco socialista, liderados pela ex-União Soviética, tendo ainda a China, algumas nações europeias, os Estados Unidos e representantes de países latino-americanos. A Conferência definiu as regras de
} 
funcionamento das relações monetárias internacionais e criou uma instituição para esse fim, denominada Fundo Monetário Internacional (FMI), encarregada de supervisionar essas regras. O sistema se embasava no denominado padrão ouro, que, por sua vez, tinha o dólar (dos EUA) como moeda de referência. Dessa forma, os EUA deveriam manter o preço do ouro em 35,00 dólares por onça e facultar a troca de dólares por ouro a esse valor sem restrições ou limitações. Assim, mantinha-se o preço fixo da moeda (dólar), e os demais países fixavam suas taxas de câmbio a partir da moeda americana. Além disso, os EUA tinham como obrigação manter a conversibilidade de sua moeda em ouro.

${ }^{3} \mathrm{Na}$ história do pensamento econômico, os mais conhecidos e influentes representantes são: Adam Smith (1723-1790), considerado o fundador do pensamento liberal e da economia política clássica; Friedrich Hayek (1899-1992); Ludwig Von Mises (1881-1973) e Milton Friedman (1912-2006).

${ }^{4}$ A OCDE é um fórum único em que os governos trabalham em conjunto para enfrentar os desafios econômicos, sociais e ambientais da globalização. A OCDE também está na vanguarda dos esforços para compreender e ajudar os governos a responder às novas evoluções e preocupações, tais como governança corporativa, a economia da informação e os desafios do envelhecimento da população. A Organização oferece um ambiente para que os governos possam comparar experiências políticas, buscar respostas para problemas comuns, identificar boas práticas e trabalhar para coordenar políticas domésticas e internacionais (OECD, 2011).

${ }^{5}$ Nas Instituições particulares (Faculdades de Filosofia), as licenciaturas se organizavam como 'licenciaturas curtas', ou seja, cursos que habilitavam professores para o Ensino Infantil e Fundamental ( $1^{\circ}$ grau), de duração menor que as chamadas licenciaturas plenas. Surgiram a partir da Lei $n^{\circ} 5.692 / 71$, num contexto em que se passou a exigir uma formação rápida e com conteúdos gerais, para atender a uma nova demanda de professores, principalmente em regiões com maior carência destes profissionais. Em 1986, o Conselho Federal de Educação propôs a extinção desses cursos, o que efetivamente ocorreu com a promulgação da Lei de Diretrizes e Bases da Educação, de 1996, os quais foram transformados, gradualmente, em licenciaturas plenas (MENEZES; SANTOS, 2002).

${ }^{6}$ Valores cotados em 2 de setembro de 2015.

${ }^{7}$ A referência mínima para a jornada extraclasse, prevista na Lei 11.738 , é de 33,33\%. Outra informação importante é que, desde fevereiro de 2015, o piso salarial nacional para os professores da Escola Básica é de R\$1.917,78, correspondente a US\$ 623,48 (cotação oficial de 4 de maio de 2015) (CONFEDERAÇÃO NACIONAL DOS TRABALHADORES EM EDUCAÇÃO, 2014).

${ }^{8}$ No entanto, um dos problemas é garantir o acesso à internet com qualidade de sinal, situação que ainda está muito distante de ser resolvida no Brasil - mesmo nos estados com melhor infraestrutura nesse setor.

\section{Referências}

BANCO CENTRAL DO BRASIL. Cotação de Moedas. [S.1], 2015. Disponível em: <http://www.bcb.gov.br>. Acesso em: 4 maio 2015.

BRASIL. Lei $n^{\circ} 5.692$, de 11 agosto de 1971. Fixa diretrizes e bases para o ensino de $1^{\circ}$ e $2^{\circ}$ graus, e dá outras providências. Diário Oficial [da] República Federativa do Brasil, Poder Executivo, Brasília, DF, 12 de agosto de 1971, Seção 1, p. 6377. Disponível em: https://bit.ly/2PHyFoj. Acesso em: 17 jan. 2012.

BRASIL. Ministério da Educação. Conselho Nacional de Educação. Câmara Superior de Educação. Parecer n. 492, de 3 de abril de 2001. Diretrizes Curriculares Nacionais dos cursos de Filosofia, História, Geografia, Serviço Social, Comunicação Social, Ciências Sociais, Letras, Biblioteconomia, Arquivologia e Museologia. Diário Oficial [da] República Federativa do Brasil, 9 de julho de 2001, Seção 1e, p. 50. Disponível em: https://bit.ly/2kWFmDM . Acesso em: 10 abr. 2018.

BRASIL. Ministério da Educação. Conselho Nacional de Educação. Câmara de Educação Superior. Resolução ${ }^{\circ}$ 14, de 13 de março de 2002. Estabelece as Diretrizes Curriculares para os Cursos de Geografia. Diário Oficial [da] República Federativa do Brasil, Poder Executivo, Brasília, DF, 9 de abril de 2002. Seção 1, p. 33. Disponível em: https://bit.ly/2zmmaVQ. Acesso em: 16 dez. 2011.

BRASIL. Lei $n^{\circ}$ 11.738, de 16 julho de 2008. Piso Salarial Profissional Nacional. Diário Oficial [da] República Federativa do Brasil, Poder Executivo, Brasília, DF, 17 de julho de 2008, Seção 1, p. 1. Disponível em: < https://bit.ly/2A7Byou>. Acesso em: 6 abr. 2015. 
BRASIL. Presidência da República. Casa Civil. Subchefia para Assuntos Jurídicos. Lei no 12.994 , de 17 de junho de 2014. Altera a Lei $\mathrm{n}^{0} 11.350$, de 5 de outubro de 2006, para instituir piso salarial profissional nacional e diretrizes para o plano de carreira dos Agentes Comunitários de Saúde e dos Agentes de Combate às Endemias. Diário Oficial [da] República Federativa do Brasil, Poder Executivo, Brasília, DF, 18 de junho de 2014, Seção 1, p. 1. Disponível em: https://bit.ly/2qYhZuH . Acesso em: 6 abr. 2015.

BRASIL. Ministério da Educação. Conselho Nacional de Educação. Resolução no 2, de $1^{\circ}$ de julho de 2015. Diário Oficial [da] República Federativa do Brasil, Poder Executivo, Brasília, DF, 2 de julho de 2015, Seção 1, p. 8-12. Disponível em: https://bit.ly/2o5nNlV . Acesso em: 9 maio 2017.

CHARLOT, Bernard. Educação e globalização: uma tentativa de colocar ordem no debate. Sísifo, [S.l.], n. 4, p. 129-136, out.-dez. 2007.

CONFEDERAÇÃO NACIONAL DOS TRABALHADORES EM EDUCAÇÃO. Tabela de salários do magistério público da educação básica 2014. Brasília, 15 de março 2016. Disponível em: https://bit.ly/1CrsFj2 . Acesso em: 5 abr. 2015.

DAHLMAN, C.; WESTPHAL, L. A transferência de tecnologia. Finanças e Desenvolvimento, Washington, EUA, v. 3, n. 4, p. 6-9, dez. 1983.

DELORS, Jacques (Org.). Educação um tesouro a descobrir: Relatório para a Unesco da Comissão Internacional sobre Educação para o século XXI. Tradução: José Carlos Eufrázio. São Paulo: Cortez; 1998. Disponível em: https://bit.ly/1XbhJC3. Acesso em: 14 maio 2017.

DEMO, Pedro. Educar pela pesquisa. 3. ed. Campinas: Autores Associados, 1998.

A valorização do professor e a pesquisa associada a educação. Observatório da Educação, São Paulo, 29 jan. 2014. Disponível em: <https://bit.ly/2R3jT8I $\geq$. Acesso em: 28 ago. 2015.

DEPARTAMENTO INTERSINDICAL DE ESTATÍSTICA E ESTUDOS SOCIOECONÔMICOS. Pesquisa Nacional da Cesta Básica de Alimentos. São Paulo, 2015. Disponível em: https://bit.ly/2Bq4jP7. Acesso em: 22 maio 2017.

DUTTA, Soma. 12 countries with the highest teacher salaries in the World. Insider Monkey, Tenafly, EUA, 30 de julho de 2015. Disponível em: https://bit.ly/2Bq5VZ8. Acesso em: 13 maio 2017.

INSTITUTO NACIONAL DE ESTUDOS E PESQUISAS EDUCACIONAIS ANÍSIO TEIXEIRA - INEP. Censo da Educação Superior. Brasília, 20 outubro 2015. Disponível em: <http://inep.gov.br/censo-da-educacao-superior>. Acesso em: 11 maio 2017.

MENEZES, Ebenezer Takuno de; SANTOS, Thais Helena dos. Sistema educacional brasileiro (verbete). In: Dicionário Interativo da Educação Brasileira - EducaBrasil. São Paulo: Midiamix Ed., 2002. Disponível em: $<$ http://www.educabrasil.com.br/eb/dic/dicionario.asp?id=173>. Acesso em: 28 nov. 2011.

MORAES, Antônio C. Robert. Geografia: pequena história crítica. São Paulo: Hucitec, 1999.

MOREIRA, Rui. O que é geografia. São Paulo: Brasiliense, 1981.

ORGANIZATION FOR ECONOMIC CO-OPERATION AND DEVELOPMENT - OECD. Education at a Glance 2011: OECD Indicators. [S.1]: OECD Publishing, 2001. Disponível em: https://bit.ly/2qY56kc. Acesso em: 06 abr. 2015. 
ORGANIZATION FOR ECONOMIC CO-OPERATION AND DEVELOPMENT - OECD. Education at a Glance 2014: OECD Indicators. [S.1]: OECD Publishing, 2014. Disponível em: http://dx.doi.org/10.1787/eag2014-en. Acesso em: 30 jun. 2015.

PEREIRA, Raquel M. F. do Amaral. Da geografia que se ensina à gênese da geografia moderna. Florianópolis: UFSC, 1999.

PISO Salarial das Profissões 2015. Tabela salarial, [S.1], 2015a. Disponível em: $<$ http://tabelasalarial.com/consulta-tabela-salarial-2014-atualizada/>. Acesso em: 7 abr. 2015.

PISO Salarial das Profissões 2015. Valor Salário Mínimo, [S.1], 2015b. Disponível em: <http://valorsalariominimo.org/piso-salarial-2014-das-profissoes/>. Acesso em: 7 abr. 2015.

PISO Salarial dos Professores 2017. Piso Salarial, [S.1], 2017. Disponível em: https://bit.ly/2S6HhlQ . Acesso em: 9 maio 2017.

SILVA, Pedro H. La universidad Latinoamericana en la época actual: tendencias, retos y propuestas innovadoras. Anales del 6to. Congreso Internacional de Educación Superior. Habana (Cuba): Congreso Internacional de Educación Superior [CD-ROM], 2008.

SORRE, Maximilien. Geografia. São Paulo: Ática, 1984.

TABELA Salarial de Professores 2015. Tabela salarial, [S.1], 2015. Disponível em: $<$ http://tabelasalarial.com/tabela-salarial-de-professores/>. Acesso em: 8 abr. 2015.

VALOR do Salário Mínimo. Tabela salarial, [S.1], 2015. Disponível em: <http://valorsalariominimo.org/pisosalarial-2014-das-profissoes/>. Acesso em: 7 abr. 2015. 